\title{
Endoskopik incelemede saptanan mide poliplerinin yerleşimi, histopatolojik tipleri ve Helikobakter pilori infeksiyonu ile ilişkisi
}

\author{
Location of endoscopic examination-detected gastric polyps, histopathological types and association \\ with Helicobacter pylori infection
}

Müjde SOYTÜRK ${ }^{1}$, Seda AKKAYA ÖZDINÇ ${ }^{1}$, Sülen SARIOĞLU², Özgül SAĞOL², Gözde Derviş HAKIM ${ }^{1}$, Ömer TOPALAK

Dokuz Eylül Üniversitesi Tıp Fakültesi, ${ }^{1}$ Gastroenteroloji Bilim Dalı, ${ }^{2}$ Patoloji Ana Bilim Dall, Izmir

\begin{abstract}
Amaç: Gastrik polipler genellikle asemptomatiktir ve endoskopik girişimler sırasında yaklassı \%2-6 oranında rastlanmaktadır. Midede en sik fundik gland polipleri ile hiperplastik polipler görülmektedir. Çalışmanın amacı DEUTFF Gastroenteroloji kliniğinde yapılan üst gastrointestinal sistem endoskopileri sırasında saptanmış mide poliplerinin yerleșim yerini, histopatolojik tiplerini ve Helikobakter pilori infeksiyonu ile olan ilişsilerini araştırmaktır. Gereç ve Yöntem: Ocak 2010 - Haziran 2011 tarihleri arasinda DEÜTF Gastroenteroloji Kliniği'nde yapılan endoskopik incelemeler sırasinda mide poli-

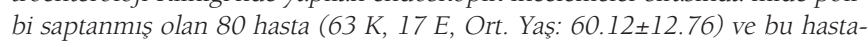
lardan çıkarılmış olan toplam 174 polibe ait veriler retrospektif olarak gözden geçirilmiștir. Bulgular: Mide polipleri 51 olguda (\%64) korpus, 19 olguda (\%24) fundus, 16 olguda (\%20) antrumda yerleșmiștir. Histolojik olarak; 38 olguda (\%47,5) hiperplastik polip, 16 olguda (\%20) fundik gland polibi, 7 olguda $(\% 8,8)$ nöroendokrin tümör, 2 olguda $(\% 2,5)$ adenomatöz polip, 1 olguda (\%1,3) hamartamatöz polip, 1 olguda $(\% 1,3)$ inflamatuar fibroid polip ve 17 olguda $(\% 21,3)$ faveolar hiperplazi saptanırken 1 olguda (\%1,3) polip spesifiye edilememiştir. Hiperplastik polipler genellikle tek bulunma eğiliminde iken fundik polipler multipl olma eğilimindeydi. Tartışma: Midede en sık görülen polipler hipeplastik poliplerdir. Hiperplastik poliplerin Helikobakter pilori enfeksiyonu ile midedeki gastrit ve intestinal metaplazi ile ilişskisi mevcuttur. Midede nöroendokrin tümör siklığı artmaktadır.
\end{abstract}

Anahtar kelimeler: Mide, polip, Helikobakter pilori, hiperplastik, fundik

\section{GİRIS}

Mide polipleri, mide epitelinden ya da submukozadan köken alan ve lümene doğru çıkıntı yapan sesil ya da saplı lezyonlardır (1). Mide poliplerine endoskopik girişimler sırasında yaklaşık \%2-6 oranında rastlanmaktadır $(2,3)$. Bunlar genellikle asemptomatik olmakla birlikte kanama, anemi, karın ağrısı ve gastrik çıkış obstrüksiyonuna neden olabildikleri bilinmektedir. Midede en sik görülen polipler hiperplastik ve fundik gland polipleri olarak bildirilmektedir. Ancak poliplerin yerleşimleri ve histolojik tipleri genellikle çalışmaların yapıldığı bölgelere göre değişiklik göstermektedir. Helikobakter pilori (Hp) enfeksiyonunun sik olduğu yerlerde hiperplastik ve adenomatöz poliplerin, fundik gland poliplerinden daha
Background/aims: Gastric polyps are usually asymptomatic and found in approximately 2-6\% of upper gastrointestinal endoscopic procedures. Hyperplastic polyps and fundic gland polyps are the two most common subtypes of gastric polypoid lesions. The aim of this study was to determine the characteristics of patients with gastric polyps diagnosed through endoscopy, the histological characteristics and location of the polyps and the presence or not of Helicobacter pylori infection. Materials and Methods: Dyspeptic patients with gastric polypoid lesions detected by upper gastrointestinal endoscopy at Dokuz Eylül University Gastroenterology Clinic between January 2010 and June 2012 were analyzed retrospectively. Data including the patients' age and sex, the number, location and histopathologic type of polyps and the presence of Helicobacter pylori infection were recorded. Eighty patients with gastric polypoid lesion (63 F, $17 \mathrm{M}$, mean age: $60.1 \pm 12.8$ years) were enrolled in the study. One-hundred and seventy-four gastric polypoid lesions were identified in 80 patients. Results: Polypoid lesions were commonly located in the corpus (64\%), followed by fundus (24\%) and antrum (20\%). The most frequently encountered histopathologic subtype of gastric polypoid lesions was hyperplastic polyp (48\%), followed by foveolar hyperplasia (21\%), fundic gland polyps (20\%), neuroendocrine tumor (9\%), adenoma (1\%), hamartomatous (1\%) and inflammatory fibroid polyp (1\%). Hyperplastic polyps were primarily single, whereas fundic gland polyps tended to be multiple. Hyperplastic polyps were associated with Helicobacter pylori infection, chronic active gastritis and intestinal metaplasia. Conclusions: The most frequently encountered histopathologic subtype of gastric polypoid lesions was hyperplastic polyp. The prevalence of neuroendocrine tumors seems to be higher than that reported earlier, most likely because of the widespread use of proton pump inhibitors.

Key words: Gastric polyp, endoscopy, Helicobacter pylori, hyperplastic, fundic

sık görüldüğü bildirilmektedir $(4,5)$. Hp enfeksiyon sıklığının az, proton pompa inhibitörü (PPI) ilaç kullanımının fazla olduğu batı ülkelerinde ise fundik gland polipleri daha sık görülmektedir $(2,6)$. Sadece poliplerin değil, polip çevresindeki mide mukozasının endoskopik ve histopatolojik özelliklerinin değerlendirilmesi hastanın tanısı ve tedavisinde önemli faydalar sağlar (7).

Bu çalışmanın amacı, mide polibi saptanan hastaların demografik özellikleri ile poliplerinin yerleşim yerleri, histopatolojik tipleri, Hp infeksiyonu ve mide mukoza değişiklikleri ile ilişkilerini araştırmaktır. 


\section{GEREÇ ve YÖNTEM}

Ocak 2010 - Haziran 2011 tarihleri arasında DEÜTF Gastroenteroloji Kliniğinde yapilan üst gastrointestinal sistem endoskopileri sırasında mide polibi saptanmış olan 80 hastaya (63 K, 17 E, Ort. Yaş: 60.12 \pm 12.76 ) ait veriler retrospektif olarak gözden geçirilmiştir. 80 hastadan çıkarılmış olan 174 polipin yerleşim yeri ile hem polip hem de gastrik mukozadan alınan biyopsilerin histopatolojk inceleme sonuçları değerlendirmeye alınmıştır.

Tüm üst gastrointestinal sistem endoskopileri sırasında midazolam (intravenöz) ile sedasyon sağlanmış ve \%10'luk lidokainin topikal yolla uygulaması ile farengeal anestezi yapılmıştır. Tüm poliplere ya koter kullanarak ya da biyopsi forsepsi ile endoskopik polipektomi uygulanmıştır. Hiçbir hastada işleme ait komplikasyon gelişmemiştir. Polip saptanan hastalarda eşlik eden mide mukozasına ait histopatolojik değişiklikleri ve $H p$ varlığını araştırmak amacıyla antrum ve korpustan en az birer adet olmak üzere multipl biyopsiler alınmıştır. Hp varlığı veya yokluğu hem hızlı üreaz test hem de histopatolojik inceleme sonucuna göre değerlendirilmiştir.

\section{BULGULAR}

Mide polipleri 51 olguda (\%64) korpus, 19 olguda (\%24) fundus, 16 olguda (\%20) antrum, 6 olguda (\%8) kardiya, 4 olguda (\%5) bulbusta ve 1 olguda $(\% 1,3)$ pilorda yerleşim göstermekteydi. Hastaların 17 (\%21,3)'sinde midede birden fazla lokalizasyonda polip saptanmıştı. Histolojik olarak; 38 olguda $(\% 47,5)$ hiperplastik polip, 16 olguda (\%20) fundik gland polibi, 7 olguda $(\% 8,8)$ nöroendokrin tümör, 2 olguda $(\% 2,5)$ adenomatöz polip, 1 olguda $(\% 1,3)$ hamartamatöz polip, 1 olguda $(\% 1,3)$ inflamatuvar fibroid polip ve 17 olguda $(\% 21,3)$ faveolar hiperplazi saptanırken 1 olguda $(\% 1,3)$ polip spesifiye edilememişti (Resim 1-5).

Olguların 33'ünde $(\% 41,3)$ tek polip mevcutken, 9 olguda $(\% 11,3)$ iki polip, 38 olguda $(\% 47,5)$ ise üç ve daha fazla polip vard. Multipl polibi olan 47 olgunun 43'ünde (\%91,5) poliplerin histolojik tipi aynı bulunurken 4 olguda $(\% 8,5)$

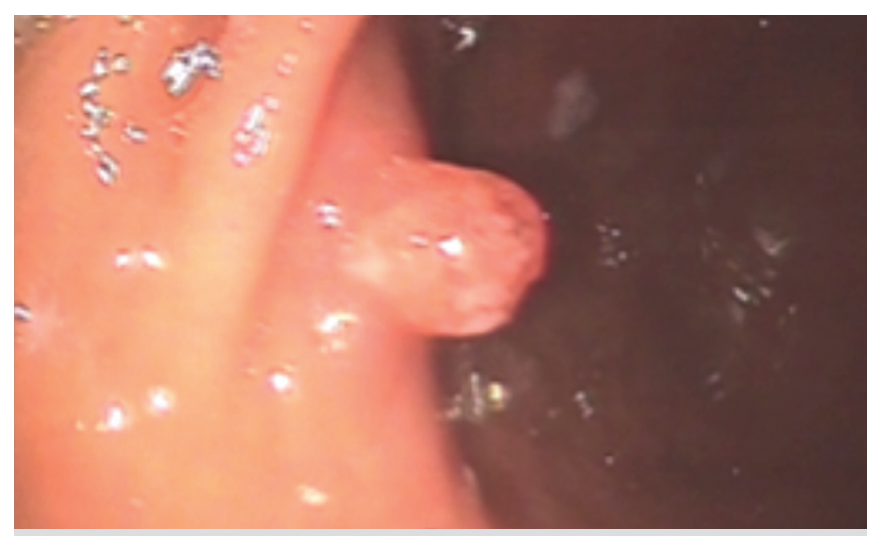

Resim 1. Hiperplastik polip.

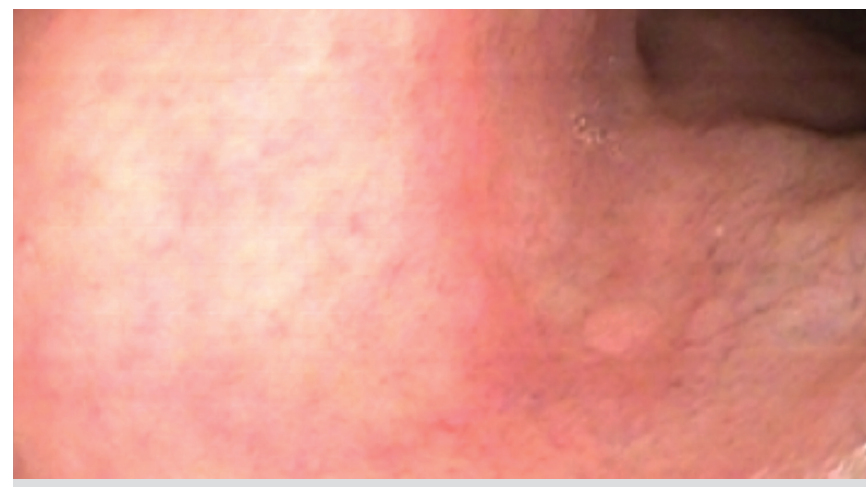

Resim 2. Fundik gland polibi.

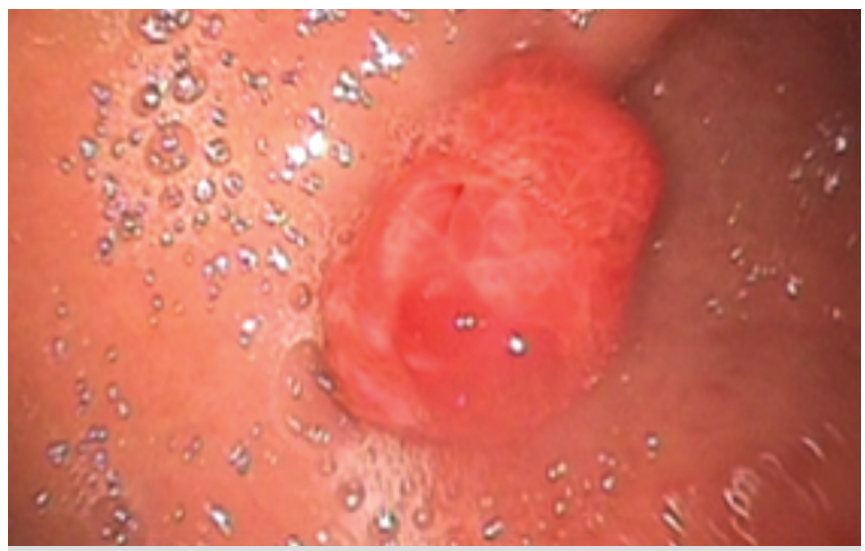

Resim 3. Adenomatöz polip.

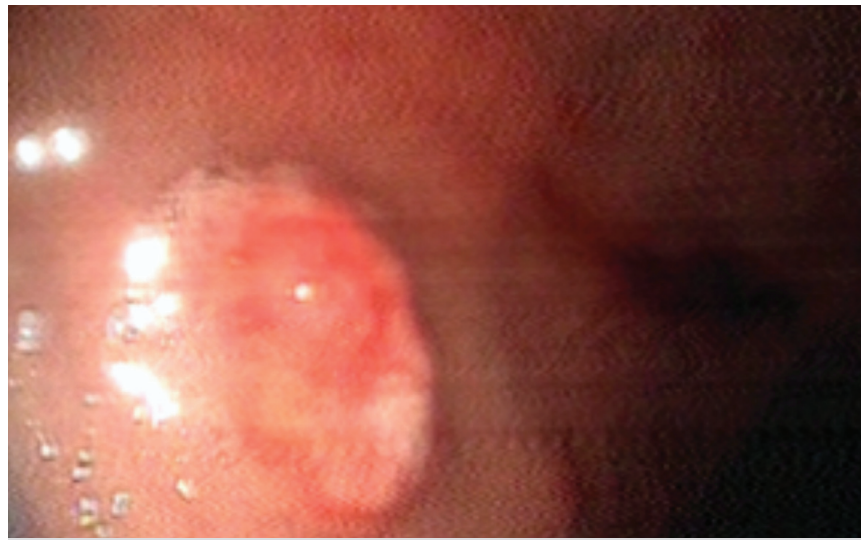

Resim 4. Nöroendokrin tümör.

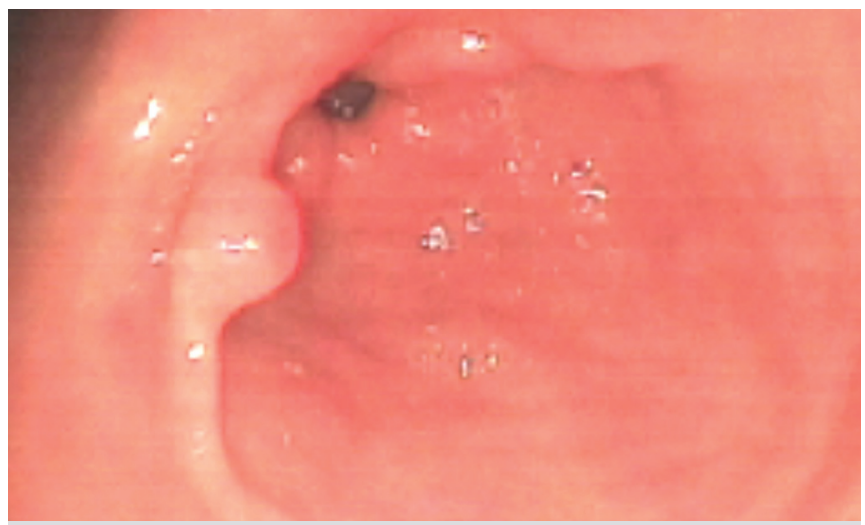

Resim 5. Hamartamatöz polip 
farklı histolojik tipte polipler olduğu saptanmıştır. Midede tek polip saptanan olgular ile 2 veya üzeri sayıda polip saptanan olguların demografik özellikleri ve poliplere ait özellikler Tablo l'de verilmiştir. Tablo l'de görüldüğü gibi multipl polip saptanan olguların yaşı, tek polip saptanan olgulara göre istatistiksel olarak anlamlı derecede daha büyük bulunmuştur (p:0,03). Gruplar arasinda cinsiyet, Hp infeksiyonu, intestinal metaplazi ve/veya atrofik gastrit varlığı açısından anlamlı fark saptanmamiştır.

Hiperplastik polip ve fundik gland polibi saptanan olgulara ait özelliklerin karşılaştırıldığı analize hem hiperplastik hem de fundik gland polibi bulunan bir olgu dahil edilmemiştir. Tablo 2'de görüldüğü gibi fundik gland polibi saptanan olguların yaşı, hiperplastik polip saptanan olgulardan anlamlı düzeyde daha yüksek bulunmuştur (p: 0,01). Fundik gland poliplerinin hepsi multipl iken hiperplastik polipler $\% 37,8$ oraninda multipl bulunuyordu ve arada anlamlı fark vardı (p: 0,01). Fundik gland polibi saptanan hastaların hiç birisinde midede intestinal metaplazi saptanmazken, hiperplastik poli-

Tablo 1. Tek ya da multipl polip saptanan olgulara ait demografik verilerin, $H$. pilori infeksiyonu, intestinal metaplazi ve atrofik gastrit sıklığının karşılaștırması

$\begin{array}{lccc}\text { Özellikler } & \begin{array}{c}\text { Tek polip } \\ \text { saptanan olgular } \\ \text { (n: 33) }\end{array} & \begin{array}{c}\text { Multipl polip } \\ \text { saptanan olgular } \\ \text { (n: 47) }\end{array} & \text { p } \\ \text { Yaş (Ortalama } \pm \text { SD) } & 56,4 \pm 13,4 & 62,7 \pm 11,8 & 0,03 \\ \text { Cins (K/E) } & 24 / 9 & 39 / 8 & \mathrm{AD} \\ \text { H. pilori infeksiyonu } & 11 & 12 & \mathrm{AD} \\ \text { n (\%) } & (\% 33,3) & (\% 25,5) & \\ \text { Intestinal metaplazi } & 9 & 14 & \mathrm{AD} \\ \text { n (\%) } & (\% 27,3) & (\% 29,8) & \\ \text { Atrofik gastrit } & 5 & 2 & \mathrm{AD} \\ \text { n (\%) } & (\% 15,2) & (\% 4,3) & \end{array}$

AD: Anlamlı değil

\begin{tabular}{|c|c|c|c|}
\hline Özellikler & $\begin{array}{l}\text { Hiperplastik } \\
\text { polip saptanan } \\
\text { olgular } \\
\text { (n: } 37)\end{array}$ & $\begin{array}{l}\text { Fundik gland } \\
\text { polibi saptanan } \\
\text { olgular } \\
\text { (n: 15) }\end{array}$ & $\mathrm{p}$ \\
\hline Yaş (Ortalama $\pm S D$ ) & $57,2 \pm 14,7$ & $67,5 \pm 6,9$ & 0,01 \\
\hline Cins (K/E) & $29 / 8$ & $13 / 2$ & $\mathrm{AD}$ \\
\hline Tek/multipl polip & $13 / 24$ & $0 / 15$ & 0,01 \\
\hline $\begin{array}{l}\text { H. pilori } \\
\mathrm{n}(\%)\end{array}$ & $\begin{array}{c}14 \\
(\% 37,8)\end{array}$ & $\begin{array}{c}2 \\
(\% 13,3)\end{array}$ & $\mathrm{AD}$ \\
\hline $\begin{array}{l}\text { Kronik aktif gastrit } \\
\mathrm{n}(\%)\end{array}$ & $\begin{array}{c}35 \\
(\% 94,6)\end{array}$ & $\begin{array}{c}10 \\
(\% 66,7)\end{array}$ & $\mathrm{AD}$ \\
\hline $\begin{array}{l}\text { Intestinal metaplazi } \\
\mathrm{n}(\%)\end{array}$ & $\begin{array}{c}14 \\
(\% 37,8)\end{array}$ & 0 & 0,01 \\
\hline $\begin{array}{l}\text { Atrofik gastrit } \\
\mathrm{n}(\%)\end{array}$ & $\begin{array}{c}3 \\
(\% 8,1)\end{array}$ & 0 & $\mathrm{AD}$ \\
\hline
\end{tabular}

AD: Anlamlı değil bi olan olguların \%37,8'inde intestinal metaplazi mevcuttu ve aradaki fark anlamlı idi (p: 0,01). Hiperplastik polibi olan olgularda $H p$ infeksiyonu sıklığı $(\% 37,8)$, fundik gland polibi olanlara $(\% 13,3)$ göre daha yüksek olmakla birlikte arada anlamlı fark saptanmadi.

Nöroendokrin neoplazili 6 olgunun 4'ünde midede intestinal metaplazi saptanırken, 2 olguda atrofik gastrit mevcuttu. Olguların hiçbirinde Hp enfeksiyonu mevcut değildi.

\section{TARTIŞMA}

Endoskopik girişimler sırasında mide poliplerinin görülme sıklığı \%2-6 oranında bildirilmektedir (2,3). Poliplerin görülme sıklığı ve histopatolojik tipleri coğrafik bölgeler arasında farklılık göstermektedir. Mide poliplerinin değerlendirildiği retrospektif bir çalışmada, mide polibi görülme yaşının 22-87 arasında değiştiği ancak özellikle 60 yaş üzeri hastalarda birden fazla polip bulunma olasılığının arttığı gözlenmiştir. Bu çalışmada en sık görülen polip tipi hiperplastik polip (\%70) olarak bildirilmiştir (4). Benzer bir çalışmaya endoskopi sırasinda polip saptanan 26.000 hasta dahil edilmiştir. Yine bu çalışmada da poliplerin \%70'ini hiperplastik poliplerin, \%12'sini adenomatöz poliplerin, \%16'sinı ise fundik gland poliplerinin oluşturduğu görülmüştür (5). Bizim çalışmamızda da hiperplastik polip (\%48) en sık görülen polip tipi idi. Bunu faveolar hiperplazi (\%21), fundik gland polipleri (\%20) ve nöroendokrin tümörler (\%9) izliyordu. Çalışmamızda midesinde tek polip saptanan hastaların yaş ortalaması 56 iken 2 veya üzerinde polip saptanan hastaların yaş ortalaması 63 idi ve arada anlamlı fark (p: 0.03) mevcuttu. Bu bulgu daha önceki çalışmaların sonuçları ile uyumludur. Başka bir deyişle 60 yaş üzeri hastalarda midede multipl polip saptanma olasilığı artmaktadır.

Hiperplastik polipler, $H p$ enfeksiyonu ve atrofik gastrit ile ilişkilidir. Hp enfeksiyonunun sık olduğu coğrafik bölgelerde hiperplastik ve adenomatöz poliplerin, fundik gland poliplerinden daha sık görüldüğü bilinmektedir $(4,5)$. Hp enfeksiyonunun fundik gland poliplerinin gelişmesine karşı koruyucu olduğu görülmüştür. Fundik gland polibi bulunan hastalarda Hp enfeksiyonu oranının düşük olduğu bildirilmektedir (2). Hp eradikasyonu ile hiperplastik poliplerin gerilediğini gösteren çalışmalar da mevcuttur $(8,9)$. Çalışmamızda hiperplastik polibi olan hastalarda $H p$ enfeksiyonu sıklığı (\%38) fundik gland polibi olanlara (\%13) göre daha yüksek olmasına rağmen arada istatistiksel olarak anlamlı fark saptanmamıştır. Bu durum vaka sayısının az olmasına bağlanabilir. Hiperplastik polibi olan hastalarda intestinal metaplazi ve atrofik gastrit saptanma oranları sırasıla \%38 ve \%8 iken fundik gland polibi olan hastaların hiç birinde intestinal metaplazi ya da atrofik gastrit mevcut değildi. Intestinal metaplazi varlığı hiperplastik polipli hasta grubunda anlamlı düzeyde yüksekti (p: 0,01). Hp enfeksiyonunun hiperplastik polipli hasta grubun- 
da daha yüksek düzeyde bulunması, intestinal metaplazi oranının yüksekliğini de açıklayabilir.

Ülkemizde yapılmış başka bir çalışmada 91 hastaya ait midedeki 150 polipoid lezyon retrospektif olarak değerlendirilmiştir. Poliplerin en sık yerleştiği lokalizasyonlar antrum (\%41), kardiya (\%27) ve korpus (\%23) olarak saptanmıştır. Poliplerin histopatolojik tipleri saptanma sıklı̆̆ına göre sırasıyla; hiperplastik (\%46), faveolar hiperplazi (\%18), fundik gland polibi (\%14), adenom (\%3) ve nöroendokrin tümör (\%1) olarak bildirilmiştir. Hp enfeksiyonu sıklığı ise \%44 bulunmuştur. Hastaların \%32'sinde multipl polip bulunduğu, hiperplastik poliplerin \%32'si multipl bulunma eğiliminde iken fundik gland poliplerinin tümünün multipl bulunduğu bildirilmiştir. Çalışmamızda poliplerin sırasıyla en sık korpus (\%64), fundus (\%24) ve antrumda (\%20) yerleştiği görülmüştür. Hastaların \%21'inde midede birden fazla lokalizasyonda polip saptanmıştır. Yukarıda sözü geçen çalışmayla benzer şekilde fundik gland poliplerinin hepsi multipl iken hiperplastik polipler \%37,8 oranında multipl bulunuyordu ve arada anlamlı fark vardı (p: 0,01).

Polipler çoğunlukla endoskopik olarak kolayca tanınabilmekle birlikte, mide lümenine protrüde olmuş her lezyon histopatolojik inceleme sonucu ile doğrulanmadan polip tanısı konulmamalıdır. Çalışmamızda, 17 hastada endoskopik olarak "polipoid lezyon" şeklinde tanımlanmış lezyonlar, histopatolojik inceleme sonucunda faveolar hiperplazi olarak tespit edilmiştir. Faveolar hiperplazinin hiperplastik poliplerin ön-

\section{KAYNAKLAR}

1. Goddard AF, Badreldin R, Pritchard DM, et al. The management of gastric polyps. Gut 2010;59:1270-6.

2. Carmack SW, Genta RM, Schuler CM, Saboorian MH. The current spectrum of gastric polyps: a 1-year national study of over 120,000 patients. Am J Gastroenterol 2009;104:1524-32.

3. Gencosmanoglu R, Sen-Oran E, Kurtkaya-Yapicier O, et al. Gastric polypoid lesions: analysis of 150 endoscopic polypectomy specimens from 91 patients. World J Gastroenterol 2003;9:2236-9.

4. Archimandritis A, Spiliadis C, Tzivras M, et al. Gastric epithelial polyps: a retrospective endoscopic study of 12974 symptomatic patients. Ital J Gastroenterol 1996;28:387-90.

5. Morais DJ, Yamanaka A, Zeitune JM, Andreollo NA. Gastric polyps: a retrospective analysis of 26,000 digestive endoscopies. Arq Gastroenterol 2007;44:14-7.

6. Jalving M, Koornstra JJ, Wesseling J, et al. Increased risk of fundic gland polyps during long-term proton pump inhibitor therapy. Aliment Pharmacol Ther 2006;24:1341-8.

7. Carmack SW, Genta RM, Graham DY, Lauwers GY. Management of gastric polyps: a pathology-based guide for gastroenterologists. Nat Rev Gastroenterol Hepatol 2009;6:331-41. cülü olabileceği düşünülmekle birlikte bu konu henüz tam olarak açıklık kazanmamıştır (10).

Nöroendokrin tümörler, polipoid lezyon olarak büyüyebilirler ve en sık korpusta bulunmalarına rağmen etiyolojiye bağlı olarak antrumda da yerleşebilirler. Genellikle düzgün yüzeyli, sesil ve geniş tabanlı nodüllerdir. Son yıllarda nöroendokrin tümörlerin sıklığının arttığına dair kanıtlar mevcuttur (11). Çalışmamızda poliplerin \%9'unu nöroendokrin tümörlerin oluşturduğu görülmüştür. Bu oran daha önce benzer çalışmalarda bildirilenlerden daha yüksektir (2-5). Olgu sayısı az olmakla birlikte bu sonuç, midede nöroendokrin tümör sıklı̆̆ının arttığını düşündürmektedir. Pernisiyöz anemi ve kronik atrofik gastrit nöroendokrin tümör gelişimi açısından risk faktörleri olarak kabul edilmektedir. Mide asidinin yokluğunda gelişen hipergastrinemi nöroendokrin hücre hiperplazisine yol açmaktadır. Bu nedenle uzun süreli PPİ ilaç kullanımının hipergastrinemiye yol açarak nöroendokrin hücre hiperplazisini uyardığı düşünülmektedir $(12,13)$. Çalışmamızda nöroendokrin tümör bulunan 6 olgunun 4'ünde midede intestinal metaplazi saptanırken, 2 olguda atrofik gastrit olduğu ve hiçbirinde Hp enfeksiyonu bulunmadığı görülmüştür.

Sonuç olarak; çalışmamızda midede en sık görülen polipler hiperplastik poliplerdir. Hiperplastik poliplerde $H p$ enfeksiyonu ile eşlik eden mide mukozasında kronik aktif gastrit ve intestinal metaplazi sıklığı yüksektir. Fundik gland polipleri 2. sıklıkta görülen poliplerdir ve multipl olma eğilimindedirler. Mide de nöroendokrin tümör sıklığı artmaktadır.

8. Ljubicić N, Banić M, Kujundzić M, et al. The effect of eradicating Helicobacter pylori infection on the course of adenomatous and hyperplastic gastric polyps. Eur J Gastroenterol Hepatol 1999;11:727-30.

9. Ohkusa T, Takashimizu I, Fujiki K, et al. Disappearance of hyperplastic polyps in the stomach after eradication of Helicobacter pylori. A randomized, clinical trial. Ann Intern Med 1998;129:712-5.

10. Oberhuber G, Stolte M. Gastric polyps: an update of their pathology and biological significance. Virchows Arch 2000;437:581-90.

11. Lawrence B, Gustafsson BI, Chan A, et al. The epidemiology of gastroenteropancreatic neuroendocrine tumors. Endocrinol Metab Clin North Am 2011;40:1-18.

12. Kokkola A, Sjoblom S, Haapiainen R, et al. The risk of gastric carcinoma and carcinoid tumours in patients with pernicious anaemia: A prospective follow-up study. Scand J Gastroenterol 1998;33:88-92.

13. Laine L, Ahnen D, McClain C, et al: Potential gastrointestinal effects of long-term acid suppression with proton pump inhibitors. Aliment Pharmacol Ther 2000;14:651-68. 